\title{
Heartbeat: is postmenopausal hormone therapy a risk factor or preventative therapy for cardiovascular disease in women?
}

Cardiovascular disease (CVD) is the leading cause of death in women in highincome countries. Most CVD events in women occur after menopause and there is a clear relationship between earlier age at menopause and increased CVD risk. Thus, it seems biologically plausible that the decrease in hormone levels after menopause might be related to CVD risk (figure 1). Yet, the potential role of postmenopausal hormone therapy (MHT) in reducing CVD risk in women remains controversial. In this issue of Heart, Gersh et $a l^{1}$ summarise the pros and cons of MHT and provide a historical overview of MHT studies, highlighting limitations such as inclusion of women with pre-existing heart disease, and the type, dose and timing of MHT. They argue that 'Human-identical hormones initiated early in menopause appear safe to be continued indefinitely, under close supervision, offering post-menopausal women greater potential for long-term CV health and improved quality of life.' Of course, 'Individualised decisionmaking is a key component of all MHT conversations; standard CVD risk reduction must be included in all therapeutic plans.'

In an editorial counterpoint, Thamman $^{2}$ disagrees with this approach because of the lack of hard clinical CVD endpoints in the more recent data. She concludes: 'Age at menopause should be taken into account as part of CVD risk stratification. However, using cardioprevention as the justification for MHT is not advisable.' On the other hand, a recent scientific statement from the American Heart Association leans toward MHT for CVD risk reduction when started within 10 years of menopause, especially in younger women. ${ }^{3}$ It is more than disappointing that in 2021 there is inadequate scientific evidence to make clear recommendations about CVD risk for a life-stage that all women

Division of Cardiology, University of Washington, Seattle, Washington, USA

Correspondence to Professor Catherine M Otto, Division of Cardiology, University of Washington, Seattle, WA 98195, USA; cmotto@uw.edu

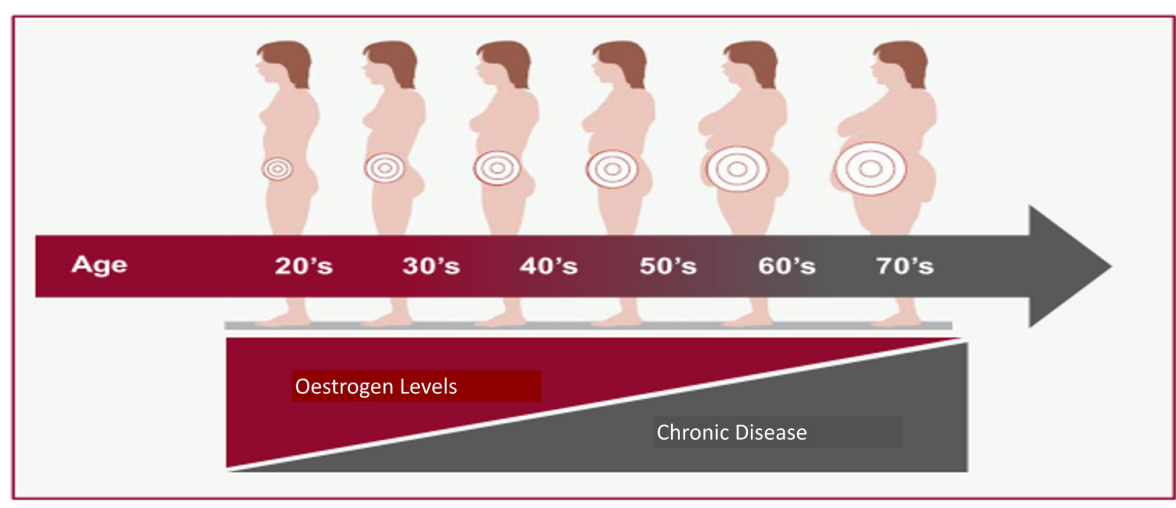

Figure 1 Age-dependent shift in oestrogen levels. Levels of oestrogen decline with age and result in increased visceral fat, higher rates of insulin resistance and an increase in cardiovascular disease.

experience. Surely those studies are long overdue.

Controversy persists regarding the optimal $\mathrm{P}_{2} \mathrm{Y}_{12}$ receptor inhibitor for patients treated with percutaneous coronary intervention (PCI) for acute myocardial infarction (MI). Venetsanos and colleagues ${ }^{4}$ found no difference in major adverse cardiovascular events at 1 year (adjusted HR 1.03, 95\% CI 0.86 to 1.24$)$ or in bleeding risk $(2.5 \%$ vs $3.2 \%$, adjusted $\mathrm{HR} 0.92$, 95\% CI 0.69 to 1.22 ) comparing 2073 patients treated with prasugrel compared with 35917 treated with ticagrelor after PCI for MI in the SWEDEHEART (Swedish Web-system for enhancement and development of evidence-based care in heart disease evaluated according to recommended therapies) registry ${ }^{4}$ (figure 2 ).

In the accompanying editorial, Professor Storey $^{5}$ provides a detailed comparison of the properties of prasugrel and ticagrelor, reminding us that these agents are preferable to clopidogrel. He then goes on to discuss potential reasons for the conflicting results reported from the ISAR-REACT-5 (Intracoronary Stenting and Antithrombotic Regimen: Rapid Early Action for Coronary Treatment-5) trial, suggesting that 'the most likely explanations for the superior outcomes [in ISARREACT-5] in the prasugrel group are (1) worse treatment adherence in patients without diabetes in the ticagrelor group

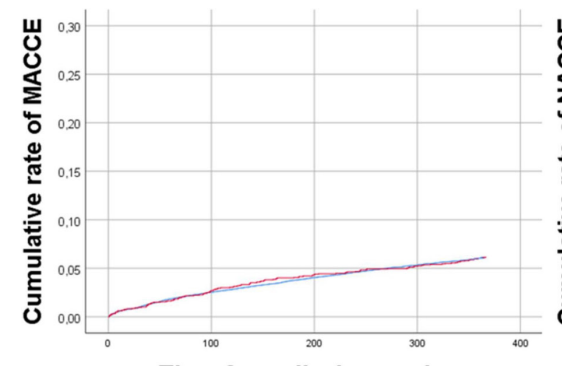

Time from discharge, days

$\begin{array}{cccc}\mathbf{0} & \mathbf{1 0 0} & \mathbf{2 0 0} & \mathbf{3 0 0} \\ 35917 & 35007 & 34461 & 33998 \\ 2073 & 2018 & 1984 & 1965\end{array}$

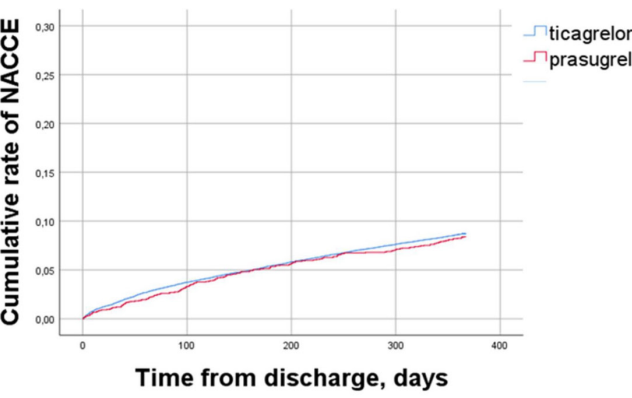

$\begin{array}{cccc}\mathbf{0} & \mathbf{1 0 0} & \mathbf{2 0 0} & \mathbf{3 0 0} \\ 35917 & 34571 & 33824 & 33177 \\ 2073 & 2005 & 1957 & 1927\end{array}$

Figure 2 Cumulative rate of adverse events stratified by treatment. Kaplan-Meier curves present the cumulative rates of major adverse cardiac and cerebrovascular events (MACCE) and net adverse cardiac and cerebrovascular events (NACCE), stratified by treatment. 


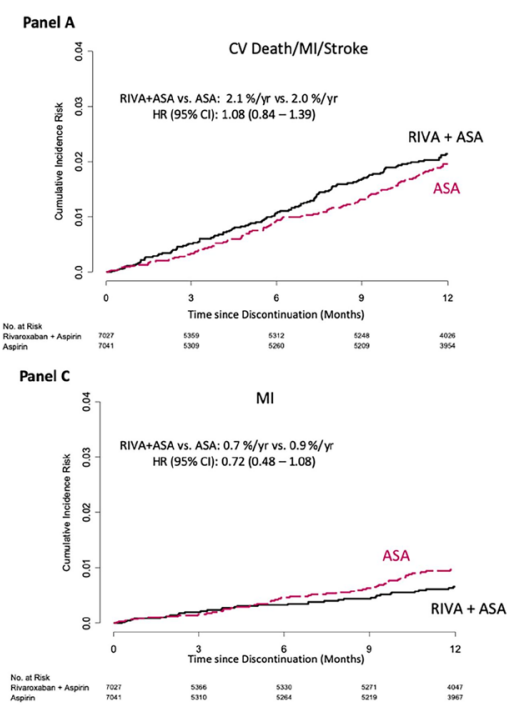

Figure 3 Outcomes from the time of switching to non-study aspirin until final contact in participants who took study antithrombotic drugs until early stopping $(n=14086)$. (A) Composite outcome panel; (B) cardiovascular death; (C) Ml; (D) stroke. ASA, aspirin; MI, myocardial infarction; RIVA, rivaroxaban.

and (2) by chance, numerically fewer non-cardiovascular deaths in the prasugrel group.' He concludes that the current data from the SWEDEHEART registry 'provide reassurance about the continued place of ticagrelor in firstline management of patients with ACS managed with PCI.'

Also in this issue of Heart is a post hoc analysis from the Cardiovascular Outcomes for People Using Anticoagulation Strategies trial which was discontinued early due to a beneficial effect of rivaroxaban in addition to aspirin in patients with chronic coronary or

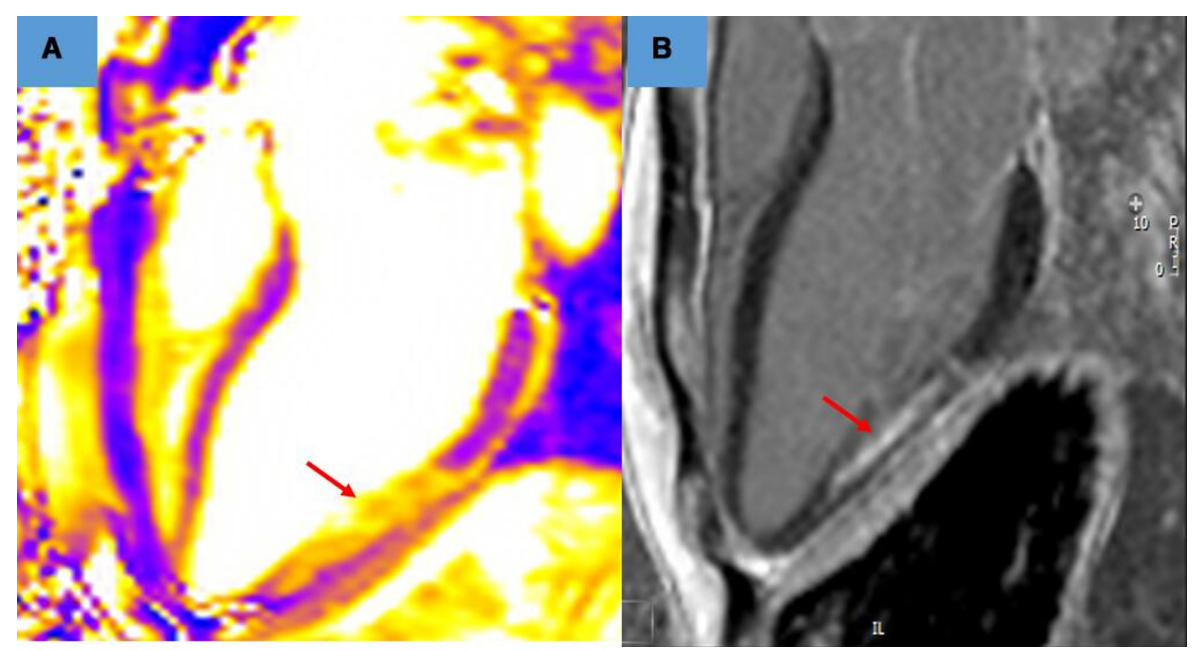

Figure 4 Cardiovascular magnetic resonance from a patient who was 13 weeks into her first pregnancy and presented with chest pain, ECG changes and an elevated troponin. An angiogram showed unobstructed coronary arteries. The figure shows T2 mapping in panel (A), with high signal (inflammation) in the mid-inferolateral wall. Panel (B) shows the cause of this to be a localised myocardial infarction. The patient went on to have a positive antiphospholipid screen and was started on anticoagulation.

peripheral artery disease. ${ }^{6}$ After early termination of the study, the benefit of therapy for incident myocardial infarction and cardiovascular death were lost and there was a higher stroke rate after switching to aspirin alone for participants who originally had been randomised to rivaroxaban in addition to aspirin (figure 3).

Darmon and Ducrocq ${ }^{7}$ address the medical, ethical and regulatory challenges when a study is terminated before approval for continuation of study medication (if effective) has been obtained. As they conclude: 'The study by Dagenais et $a l^{6}$ sheds light on the various serious consequences of discontinuing study treatments that were proven effective in randomised clinical trials. It should be seen as a call for developing strategies for management of patients after trial completion, whether it is earlier than expected or scheduled.'

The Education in Heart article in this issue summarises the cardiovascular manifestations of systemic inflammatory diseases. ${ }^{8}$ Advanced cardiac imaging approaches have greatly expanded our understanding of the frequency, type and extent of cardiac involvement in patients with conditions such as systemic lupus erythematosus, antiphospholipid syndrome, systemic sclerosis, autoimmune myositis and the vasculitides. A detailed summary table will be invaluable to clinicians, along with imaging examples of cardiac involvement (figure 4).

The Cardiology-in-Focus article in this issue ${ }^{9}$ provides a concise guide to minimising risk for women, such as cardiology trainees and consultants, who work with radiation during pregnancy and points out that: 'A better awareness of radiation protection-with more use of low-dose techniques and protective equipmentwould benefit all operators and not just those who are pregnant.'

Funding The authors have not declared a specific grant for this research from any funding agency in the public, commercial or not-for-profit sectors.

Competing interests None declared.

Patient and public involvement Patients and/or the public were not involved in the design, or conduct, or reporting, or dissemination plans of this research.

Patient consent for publication Not required.

Provenance and peer review Commissioned; internally peer reviewed.

(C) Author(s) (or their employer(s)) 2021. No commercial re-use. See rights and permissions. Published by BMJ.

\section{Check for updates}

To cite Otto CM. Heart 2021;107:1103-1105.

Heart 2021;107:1103-1105

doi:10.1136/heartjnl-2021-319791

\section{ORCID iD}

Catherine M Otto http://orcid.org/0000-0002-05279392

\section{REFERENCES}

1 Gersh FL, O'Keefe JH, Lavie CJ. Postmenopausal hormone therapy for cardiovascular health: the evolving data. Heart 2021;107:1115-22.

2 Thamman R. Are we there yet? menopausal hormone therapy for primary cardiovascular disease prevention. Heart 2021;107:1106-8.

3 El Khoudary SR, Aggarwal B, Beckie TM, et al. Menopause transition and cardiovascular disease risk: implications for timing of early prevention: a scientific statement from the American heart association. Circulation 2020;142:e506-32. 
4 Venetsanos D, Träff E, Erlinge D. Prasugrel versus ticagrelor in patients with myocardial infarction undergoing percutaneous coronary intervention. Heart 2021;107:1145-51.

5 Storey RF. Ticagrelor versus prasugrel for PCl-managed myocardial infarction: the battle of the giants continues. Heart 2021;107:1111-2.
6 Dagenais GR, Dyal L, Bosch JJ. Cardiovascular consequences of discontinuing low-dose rivaroxaban in people with chronic coronary or peripheral artery disease. Heart 2021;107:1130-7.

7 Darmon A, Ducrocq G. Early stopping of a randomised trial for efficacy: a medical, ethical and regulatory challenge. Heart 2021;107:1109-10.
8 Sen G, Gordon P, Sado DM. Cardiac manifestations of rheumatological disease: a synopsis for the cardiologist. Heart 2020;107:1173-81.

9 Wood A, Hussain ST. Working with radiation in pregnancy: a guide for cardiologists. Heart 2021;107:1182-3. 